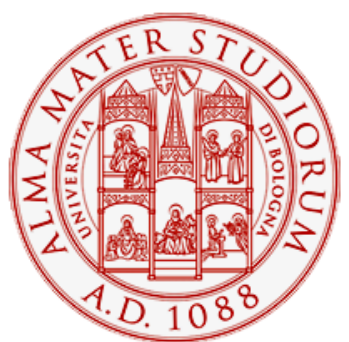

Alma Mater Studiorum - Università di Bologna DEPARTMENT OF ECONOMICS

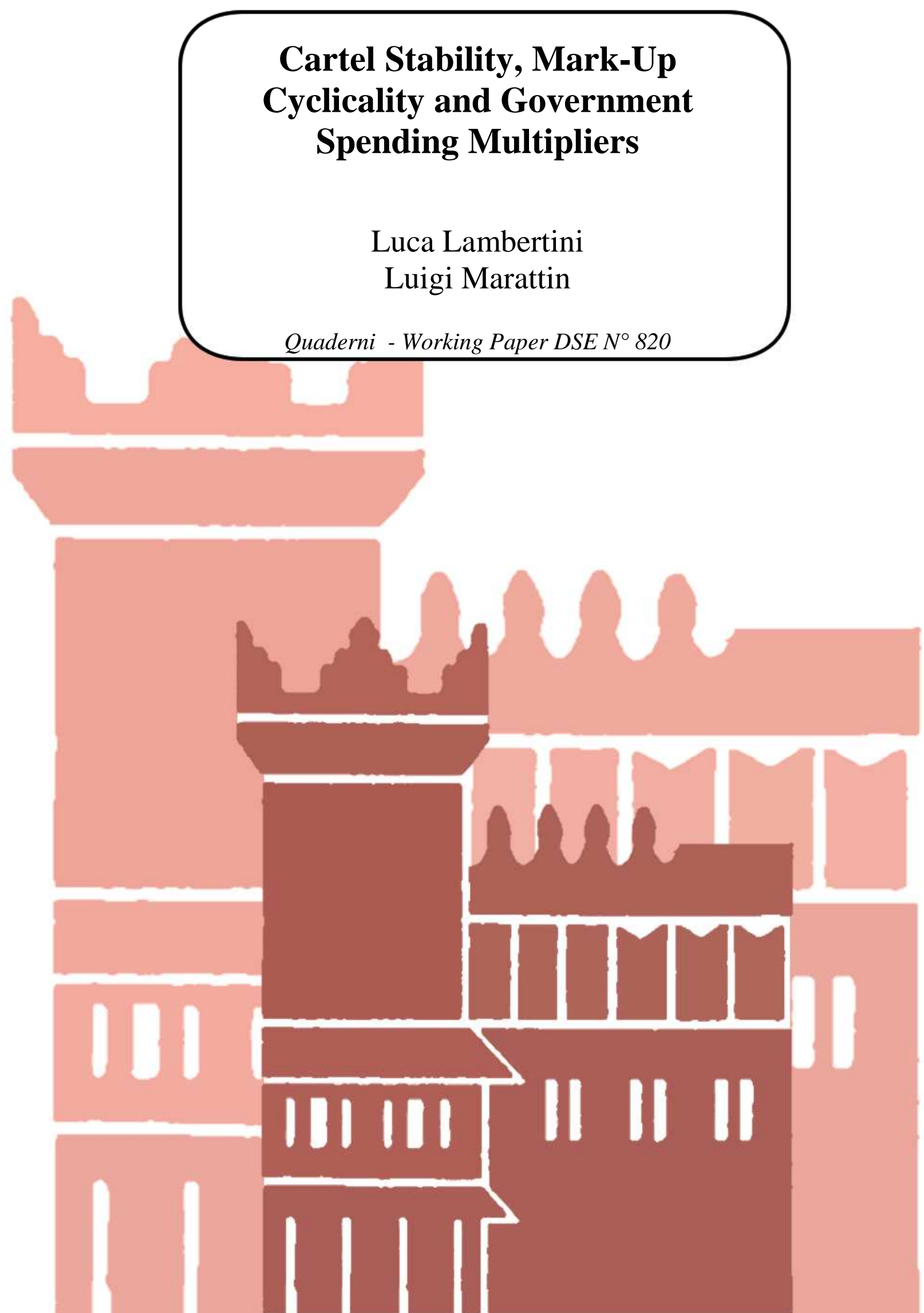




\title{
Cartel Stability, Mark-Up Cyclicality and Government Spending Multipliers*
}

\author{
Luca Lambertini and Luigi Marattin \\ Department of Economics, University of Bologna \\ Strada Maggiore 45, 40125 Bologna, Italy \\ luca.lambertini@unibo.it; luigi.marattin@unibo.it
}

March 23, 2012

\begin{abstract}
Mark-up cyclical behaviour is relevant in determining the size of government spending multiplier on output. While theoretical literature priviliged the counteryclical hypothesis, empirical evidence is far from being conclusive. Based on seminal Rotemberg and Saloner (1986) contribution, we build a theoretical framework based on Bertrand duopoly, stochastic demand and product differentiation, where the analysis of cartel stability under partial collusion points towards procyclical pricing. According to the intensity of marginal cost cyclicality, this can produce a procyclical mark up or - at least - render it less countercyclical than expected, with relevant effects on the transmission mechanism of government spending stimuli.
\end{abstract}

JEL Codes: C73, L13

Keywords: partial collusion, cyclical pricing

*We would like to thank Giacomo Calzolari, Paolo Manasse and Antonio Minniti per precious comments and suggestions. The usual disclaimer applies. 


\section{Introduction}

Recent theoretical contributions (Hall, 2009; Woodford, 2011) highlight the importance of price mark-up's cyclical behaviour for the transmission mechanism of fiscal policy. Previous literature (Galì et al., 2005; Galì, 2005) had already stressed that an exogenous reduction in the aggregate inefficiency wedge (price or wage mark-up) amplifies the effects of a government spending stimulus on aggregate demand, and vice versa. However, by relating mark-up movements to the business cycle, it is possible to investigate analytically the relationship between government spending multipliers and the degree of pro/countercyclicality of mark-up. In a stylized sticky prices macroeconomic model, Hall shows that if we define $\mu(y)=y^{-\omega}$ as the price mark-up, and parameter $\omega$ indicates the sensitivity to the income level $y$, then:

$$
\operatorname{sign}\left[\frac{\partial\left(\frac{d y}{d g}\right)}{\partial \omega}\right]=\operatorname{sign}(\omega)
$$

Considering that the government spending multiplier is positive, equation (1) means that if the mark-up is countercyclical $(\omega>0)$ then the higher the sensitivity to aggregate demand $(\omega \uparrow)$, the higher the government spending multiplier $\left(\frac{d y}{d g} \uparrow\right)$. On the other hand, if mark-up is procyclical $(\omega<0)$, a more pronounced cycle elasticity $(\omega \uparrow)$ lowers the expansionary effects of government purchases on output $\left(\frac{d y}{d g} \downarrow\right)$.

What does economic literature have to say about the direction of mark-up cyclicality?

Theoretical literature has mainly focused on countercyclicality, ${ }^{1}$ by taking two alternative roads that we could label "the macroeconomic view" and "the industrial organization view".

As to the former, the traditional explanation has centered on nominal rigidities: if prices are sticky, an increase in aggregate demand - assuming

\footnotetext{
${ }^{1}$ Lindbeck and Snower (1987) and Bils (1987) achieve mark-up countercyclicality by establishing a positive relationship between aggregate demand and elasticity of demand. Edmond and Veldkamp (2009) assign the central role to income distribution: during booms, income shifts towards the lower tail of the distribution, featured by higher-elasticity consumers.
} 
flexibility of some elements of marginal costs - results in a mark-up reduction (Rotemberg and Woodford 1999, Woodford 2003).

The industrial organization view focuses instead on firms' strategic interaction in a non-competitive environment. Rotemberg and Saloner (1986) argue that oligopolies are likely to behave more competitively when demand rises, especially when price is the strategic variable. Under these circumstances, in fact, the benefit from deviation is larger, and the punishment is diminished because it will be implemented when the expansionary demand shock will have already been absorbed. As a results, price/marginal cost ratio declines as aggregate demand increases. Haltiwanger and Harrington (1991) extend the analysis to allow for time-varying firms'expectations on future demand, by relaxing the assumption of i.i.d. demand shocks so to induce serial correlation in the cycle. They highlight potential asymmetries in collusive pricing behavior across different state of the business cycle, as their findings show that collusion is more difficult during recessions than during booms. In fact, establishing a relation between future and current demand induces asymmetries between the opportunity costs of engaing in price wars according to the direction of demand. Under falling demand, the forgone collusive profits are on a intertemporally decreasing path, so the incentive to collude is lower and likely to remain so. On the other hand, in a period of increasing demand, the traditional Rotemberg and Saloner result is mitigated by the fact that joint-maximizing profits are going to be higher in the future. Along this path, Bagwell and Staiger (1997) develop a theory of collusive pricing in a framework where aggregate demand alternates stochastically between slow and fast growth states, and where the transition is governed by a Markov process. They find that the cyclical behaviour of collusive prices depends crucially on correlation of demand growth rates through time and the expected duration of boom and recessions. Particularly, collusive prices are procyclical in presence of positive demand correlation through time, and countercyclical otherwise. Furthermore, the amplitude of the collusive pricing is larger when the recession has a longer expected duration or - conversely- when the boom has a lower lenght. Those two contributions stress that the qualitative and quantitative dimensions of collusive pricing can differ according to the state of the business cycle. Such an asymmetry in the intensity of the collusion is directly related to the mark-up cyclical behaviour and thus - as we will argue - to the size of government spending multipliers. Therefore, those results might provide an explanation for multipliers' asymmetries over the business 
cycle (Canzoneri et al., 2011) ${ }^{2}$.

More recently, a new strand of literature combines traditional general equilibrium macro models with an industrial organization approach, emphasizing the procyclicality of entry in determining mark-up countercyclicality, through the competition effect (Ghironi and Melitz 2005, Jaimovich and Floetotto 2008, Etro and Colciago 2010)

However, how empirically robust is the evidence about mark-up countercyclicality?

Although a considerable number of contributions points towards countercyclicality, ${ }^{3}$ empirical literature on mark-up cyclical behaviour is not unambiguous. Donowitz et al. $(1986,1988)$ find evidence on procyclicality in the US; Chirinko and Fazzari (1994) use a dynamic factor model to estimate markups, finding that they are procyclical in nine of the eleven 4-digit industries they analyze. Updating Bils (1987) analysis - in favor of countercyclicality - with more recent and richer data, Nekarda and Ramey (2010) find that all measures of markups are either procylical or acyclical.

Hall (2009) provides a simple first-cut test for cyclicality by noting that the mark-up can be expressed as the ratio between the elasticity of output with respect to labor input $\left(\frac{\partial Y}{\partial L} \frac{L}{Y}\right)$ and the share of labor compensation over nominal income $\left(\frac{W L}{P Y}=s\right)$. In fact, since by the envelope theorem property, a cost-minimizing firm equalizes the marginal cost of increasing output across all possible margins for varying production, we can express marginal cost as:

$$
M C=\frac{W}{\frac{\partial Y}{\partial L}}
$$

As gross mark-up $(=\mu)$ is defined as the ratio between price index and marginal costs,and multiplying and dividing by $\frac{Y}{L}$, then:

$$
\mu=\frac{\frac{\partial Y}{\partial L} \frac{L}{Y}}{s}
$$

\footnotetext{
${ }^{2}$ Rotemberg and Woodford (1992) develop the idea of mark-up countercyclicality in a dynamic general equilibrium setting, finding that the model's empirical performances are closer to actual postwar US data than the corresponding predictions of the perfectly competitive model.

${ }^{3}$ See Martins (1996) on OECD, Chevalier et al. (2003) on the US, Portier (1995) on France.
} 
If the production process is approximated by a Cobb-Douglas $Y=L^{\alpha} K^{1-\alpha}$, then the numerator of (2) is $\alpha$ and can be considered relatively stable over time. Thus, the countercyclicality of the mark-up $\mu$ requires the procyclicality of labor share $s$.

Figure 1 shows the dynamics of labor share and output in five major OECD economies from 1990 to 2009.
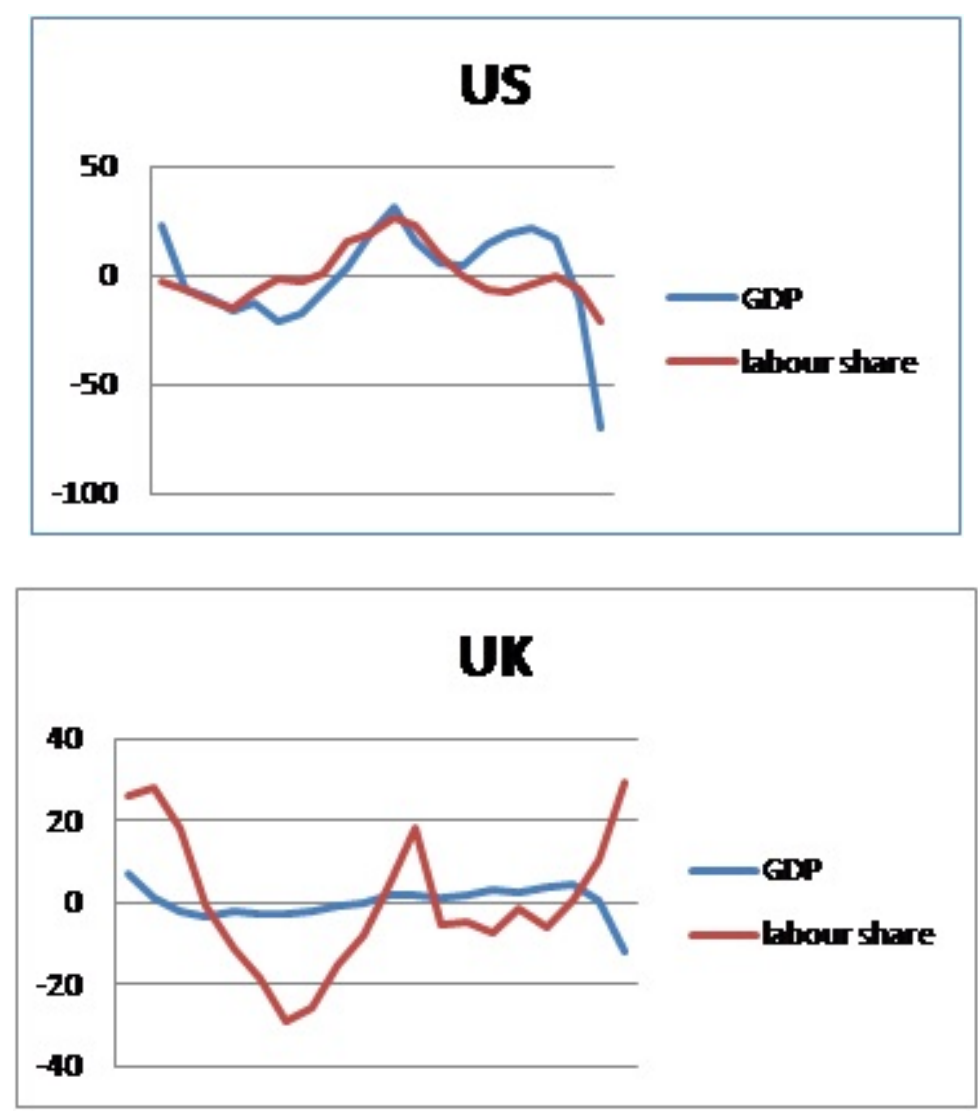


\section{France}
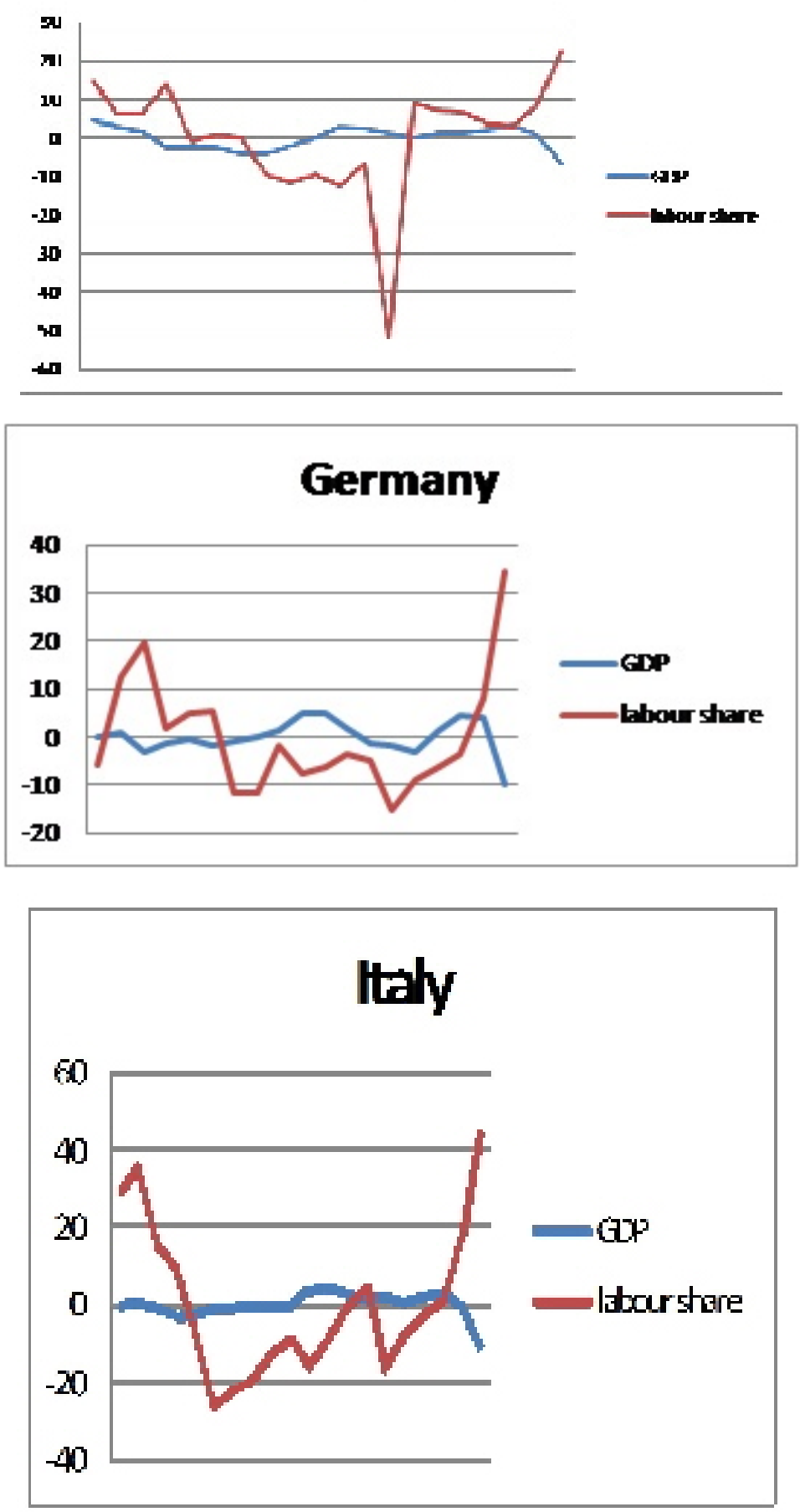
We can notice that labour share is far from showing an unambigous procyclical behaviour ; table 1 reports a simple correlation analysis showing that - with the exception of US - there seems to be a negative rather than positive correlation between labor share and the business cycle.

Table 1: Correlation between detrendend GDP and labour share

\begin{tabular}{|l|l|}
\hline COUNTRY & CORRELATION \\
\hline US & 0.61 \\
\hline UK & 0 \\
\hline FRANCE & -0.12 \\
\hline GERMANY & -0.52 \\
\hline ITALY & -0.49 \\
\hline
\end{tabular}

In this paper, we present a theoretical framework based on strategic interaction able to rationalize the existence of pro-cyclical pricing. Our benchmark model is the one put forward by Rotemberg and Saloner (1986). We indeed set out by offering a brief summary of their analysis, reconstructing the countercyclical behavour of prices in a simple repeated duopoly game with homogeneous goods, in which demand is subject to random shocks affecting the reservation price. In addition to their result, we show that increasing the probability of a positive shock brings about an increase in cartel stability, which could be large enough to more than counterbalance the effect identified by Rotemberg and Saloner. Then, we review the established IO debate on the behaviour of firms involved in an implicitly collusive price supergame under product differentiation and perfect certainty, producing well defined procyclical conclusions. Our effective contribution consists in bridging the two approaches, pursuing two distinct but related goals: (i) to characterise the maximum degree of collusion (i.e., the highest collusive price) that can be sustained in a stochastic environment, given time preferences and product differentiation; and (ii) to check whether the counterciclity emerging under stochastic demand and perfect product substitutability can indeed be compatible with the seemingly opposite result produced by the traditional cartel theory belonging to IO, in which much emphasis is posed on product differentiation but this is accompanied by perfect certainty. Our analysis indeed shows that, provided unilateral deviations grant monopoly power, Rotemberg 
and Saloner's countercyclical pricing can be seen as the limit of a general model in which, for sufficiently high (low) degrees of product differentiation, procyclical (countercyclical) pricing obtains.

The rest of paper proceeds as follows. Section 2 recalls the Rotember and Saloner's framework, generalized in stochastic demand framework. Section 3 inserts product differentiation and proves that this feature reverts the traditional countercyclical pricing of the benchmank model. In section 4 we provide a framework able to bridge the two positions. Finally, section 5 concludes.

\section{Preliminaries: the status-quo.}

We set out by briefly summarising first Rotemberg and Saloner's (1986) model of countercyclical pricing, and then the features of implicitly collusive pricing in supergame-theoretic models deeply investigated in the industrial organization literature.

\subsection{Countercyclical pricing}

The following is a simplified version of their setup, in which we will focus on the behaviour of a cartel formed by two (instead of $n$ ) firms, without further loss of generality. ${ }^{4}$ As in their paper, we consider a market for a homogenous good, over an infinite horizon. Time $t$ is discrete, with $t=0,1,2, \ldots \infty$, and the demand function at any time $t$ is $p_{t}=\sigma_{t}-q_{1 t}-q_{2 t}$, with $q_{i t} \geq 0$ being firm $i$ 's output. Firms have identical technologies represented by the cost function $C_{i}=c q_{i}$, with $\sigma_{t}>c \geq 0$. To ease the exposition throughout the paper, and again w.l.o.g., we set $c=0$. The profit function of the individual firm thus coincides with revenues, $\pi_{i}=p q_{i}$. The reservation price $\sigma_{t}$ is stochastic, and in each period can take one of two values, $a>b$, with probabilities $\mathfrak{p}(a)=m$ and $\mathfrak{p}(b)=1-m$, respectively, with $m \in[0,1]$.

The supergame unravels following the rules of Friedman's (1971) perfect folk theorem, whereby any unilateral deviation from the collusive path

\footnotetext{
${ }^{4}$ This exposition relies on (and slightly generalises) the simplified version of the countercyclical pricing model in Tirole (1988, pp. 248-250).
} 
is punished by a permanent reversal to the Nash equilibrium of the constituent stage game forever (the so-called grim trigger strategy). In the present setting, product homogeneity entails that the per-period profits at the Bertrand-Nash equilibrium are nil. As in Rotemberg and Saloner (1986), suppose firms (i) set prices after having observed the state of demand (either $a$ or $b$ ), and (ii) collude at the monopoly price in each period. Later, we will come to the case of partial collusion.

At any $t$, monopoly price $p_{t}^{M}=\sigma_{t} / 2$ delivers the individual expected cartel profit:

$$
E \pi^{C}=\frac{m \pi^{M}(a)+(1-m) \pi^{M}(b)}{2}=\frac{m a^{2}+(1-m) b^{2}}{8} .
$$

If a firm contemplates the possibility of deviation, the best option is to do so in a period of high demand, so that slightly undercutting the monopoly price grants the cheating firms full monopoly profits in that period, $\pi^{D}=$ $a^{2} / 4$. As already explained above, such deviation at any $t$ is punished by driving profits to zero from $t+1$ to doomsday through the adoption of the marginal cost pricing rule at the Bertrand-Nash equilibrium. Assuming firms share identical time preferences measured by a symmetric and time-invariant discount factor $\delta \in(0,1)$, the stability of price collusion requires $\delta$ to meet the following necessary and sufficient condition:

$$
E \pi^{C} \sum_{t=0}^{\infty} \delta^{t} \geq \pi^{D} \Leftrightarrow \frac{a^{2}[1-\delta(1+m)]+b^{2}(1-m) \delta}{8(1-\delta)}
$$

which is satisfied by all

$$
\delta \geq \frac{a^{2}}{a^{2}(1+m)+b^{2}(1-m)} \equiv \delta^{*},
$$

with

$$
\frac{\partial \delta^{*}}{\partial a}=\frac{2 a b^{2}(1-m)}{\left[a^{2}(1+m)+b^{2}(1-m)\right]^{2}}>0 \forall m \in[0,1) .
$$

Property (6) indicates that the critical threshold of the discount factor stabilising full collusion increases with the good state. This is one of the elements leading to the (by now classical) interpretation of this model, according to which firms should collude less if demand gets higher, as the size of the market ensures high profits anyway, and this this suggests the idea of counterciclical pricing. This argument is reinforced if one examines the perspective 
of activating some degree of partial collution at the highest $p^{P} \in\left(0, p^{M}\right)$ sustainable for $\delta<\delta^{*}$.

All of the above is based on comparative statics taken w.r.t. $a$. Another possibility (not examined in Rotemberg and Saloner, 1986) is to assess the effect of a change in $m$ on cartel stability:

$$
\frac{\partial \delta^{*}}{\partial m}=-\frac{a^{2}(a-b)(a+b)}{\left[a^{2}(1+m)+b^{2}(1-m)\right]^{2}}<0 \forall m \in[0,1)
$$

revealing that an increase in the probability attached to the good state makes full collusion easier to sustain. This, on the contrary, has a definite procyclical flavour. Moreover, using (6-7), we can construct the marginal rate of substitution between $a$ and $m$ as follows:

$$
\frac{d a}{d m}=-\frac{\partial \delta^{*}}{\partial m} \cdot \frac{\partial a}{\partial \delta^{*}}=\frac{a(a-b)(a+b)}{2 b^{2}(1-m)}>0,
$$

illustrating the complementarity between $a$ and $m$. Correspondingly, $\delta^{*}$ yields the map appearing in Figure 1, with $\delta_{1}^{*}>\delta_{2}^{*}>\delta_{3}^{*}$. The curves are upward sloping and convex in $m$, for all $m \in[0,1]$ and $a>b$. Hence, given any admissible value of $m$, an increase in $a$ makes it more difficult for firms to sustain collusion along the frontier of monopoly profits. Conversely, however, given any $a>b$, an increase in $m$ generates the opposite effect. Overall, the balance between the two may indeed leave the critical threshold unmodified. This suggests that, if probabilities can be generated of at least affected by a policy maker's announcements, a governement might indeed exploit its own credibility to influence firms' pricing behaviour in the desired direction. 
Figure 1: The critical discount factor for full collusion in the space $(m, a)$.

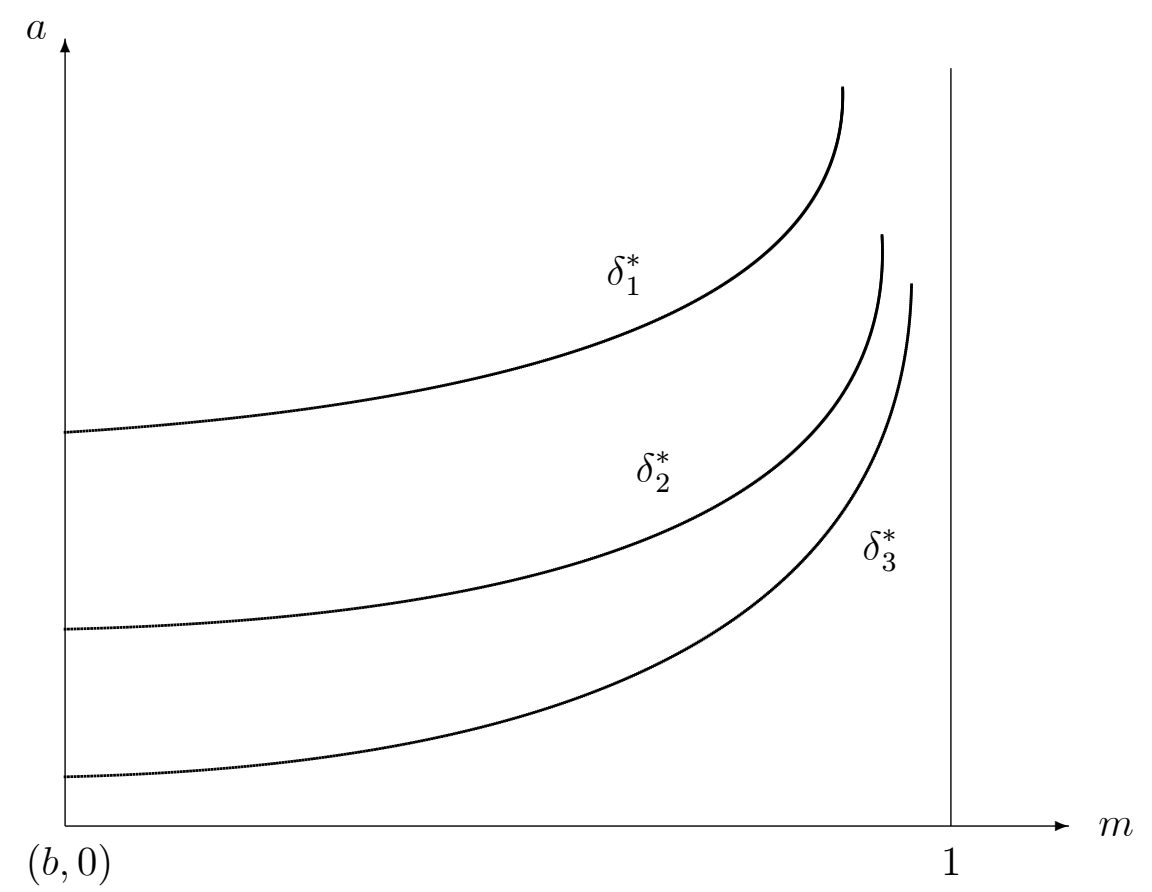

We may summarise the above exposition into the following:

Lemma 1 Under demand uncertainty and product homogeneity, any positive shock on demand increasing the level of the reservation price in the best state makes price collusion more difficult to sustain, all else equal.

\subsection{Implicit price collusion in oligopoly supergames}

The standard approach in industrial organization theory rules out uncertainty to focus instead on the bearings of product differentiation on the intensity and stability of implicit collusion. ${ }^{5}$ Accordingly, we consider a market where two single-product firms offer differentiated products over discrete time

\footnotetext{
${ }^{5}$ The material appearing in this section is a compact exposition of a large debate. See Deneckere (1983), Majerus (1988), Chang (1991, 1992), Rothschild (1992), Ross (1992), Lambertini (1997) and Albæk and Lambertini (1998), inter alia.
} 
$t=0,1,2,3, \ldots \infty$. At any $t$, the inverse demand function for variety $i$ is (see Spence, 1976; and Singh and Vives, 1984, inter alia):

$$
p_{i}=a-q_{i}-s q_{j}
$$

where $s \in[0,1]$ is the symmetric degree of substitutability between any pair of varieties. If $s=1$, products are completely homogeneous; if instead $s=0$, strategic interaction disappears and firms are independent monopolists over $n$ separated markets. The direct demand function to be used under Bertrand behaviour obtains by inverting the system (9):

$$
q_{i}=\frac{a}{1+s}-\frac{p_{i}}{1-s^{2}}+\frac{s p_{j}}{1-s^{2}} .
$$

As in the previous model, firms share the same technology, summarised by the cost function $C_{i}=c q_{i}$, wit marginal cost $c$ being normalised to zero for the sake of simplicity. Therefore, per-period individual profits are $\pi_{i}=p_{i} q_{i}$. Throughout the game, firms also share the same intertemporal preferences measured by the constant discount factor $\delta \in(0,1)$.

The perfect folk theorem yields the following condition, that must be satisfied in order for the collusive path to be stable:

$$
\pi^{C} \sum_{t=0}^{\infty} \delta^{t} \geq \pi^{D}+\pi^{N} \sum_{t=1}^{\infty} \delta^{t}
$$

where, unlike the previous model, $\pi^{N} \geq 0$ is the profit generated by the Bertrand-Nash equilibrium of the constituent game; it is positive whenever some degree of product differentiation exists. Likewise, product differentiation entails that $\pi^{D} \in\left(\pi^{C}, 2 \pi^{C}\right]$, i.e., the cheating firm may not necessarily stand alone in the market in the deviation period.

Four relevant cases are to be examined:

- firms' time preferences allow for full collusion at the pure monopoly price, and product differentiation is high enough to allow the cheated firm to operate on the market with positive market share and profits in the deviation period;

- firms' time preferences allow for full collusion at the pure monopoly price, but product differentiation is low enough to cause the cheated firm's market share and profits to fall to zero in the deviation period; 
- firms' time preferences only allow for some degree of partial collusion, and product differentiation is high enough to allow the cheated firm to operate on the market with positive market share and profits in the deviation period;

- firms' time preferences only allow for some degree of partial collusion, but product differentiation is low enough to cause the cheated firm's market share and profits to fall to zero in the deviation period.

What is common to all of the above four cases is the per-period BertrandNash profit $\pi^{N}$ appearing on the r.h.s. of (11), that can be quickly worked out once and for all.

The first order condition for the maximization of $\pi_{i}$ w.r.t. $p_{i}$ is

$$
\frac{\partial \pi_{i}}{\partial p_{i}}=\frac{a(1-s)-2 p_{i}+s p_{j}}{1-s^{2}}=0
$$

whereby the symmetric Bertrand-Nash equilibrium price is

$$
p^{N}=\frac{a(1-s)}{2-s}
$$

with profits

$$
\pi^{N}=\frac{a^{2}(1-s)}{(1+s)(2-s)^{2}},
$$

both falling to zero in the homogeneous good case.

\subsubsection{Full collusion}

Under full collusion, both firms set the monopoly price

$$
p^{M}=\frac{a}{2}
$$

which yields the symmetric share of monopoly profits

$$
\pi^{C}=\frac{a^{2}}{4(1+s)}=\frac{\pi^{M}}{2}
$$

to each firm. 
Now look at the deviation period, and suppose the cheated firms remains on the market selling a positive output. The optimal deviation is the best reply to $p^{M}$, i.e.:

$$
p^{D}\left(p^{M}\right)=\frac{a(2-s)}{4}
$$

which is viable as long as the resulting sales volume of the firm remaining loyal to the cartel is positive, which requires

$$
s \in[0, \sqrt{3}-1) .
$$

The deviation profits are

$$
\pi^{D}=\frac{a^{2}(2-s)^{2}}{16\left(1-s^{2}\right)} .
$$

If instead $s \in(\sqrt{3}-1,1]$, then the cheated firm is out of business and the deviator stands alone on the market place. In this range, the deviation price solves

$$
q^{c h}=\frac{a}{1+s}-\frac{p^{M}}{1-s^{2}}+\frac{s p^{D}}{1-s^{2}}=0,
$$

yielding

$$
p^{D^{\prime}}\left(p^{M}\right)=\frac{a(2 s-1)}{2 s}
$$

delivering deviation profits equal to

$$
\pi^{D^{\prime}}\left(p^{M}\right)=\frac{a^{2}(2 s-1)}{4 s^{2}} .
$$

Then one can easily verify that

$$
p^{D}\left(p^{M}\right)=p^{D^{\prime}}\left(p^{M}\right) \text { and } \pi^{D}\left(p^{M}\right)=\pi^{D^{\prime}}\left(p^{M}\right)
$$

in correspondence of $s=\sqrt{3}-1$.

We can now turn to the derivation of the critical thresholds of the discount factor $\delta$, above which full collusion is sustainable in the two cases. For all $s \in[0, \sqrt{3}-1),(19)$ is the relevant deviation profit, and the critical threshold of the discount factor above which full collusion in prices is stable is

$$
\delta_{B}^{*}=\frac{\pi^{D}\left(p^{M}\right)-\pi^{M}}{\pi^{D}\left(p^{M}\right)-\pi^{B N}}=\frac{(2-s)^{2}}{8(1-s)+s^{2}}
$$


while for all $s \in(\sqrt{3}-1,1]$, i.e., in the region where $(22)$ applies, it is

$$
\delta_{B}^{*^{\prime}}=\frac{\pi^{D^{\prime}}\left(p^{M}\right)-\pi^{M}}{\pi^{D^{\prime}}\left(p^{M}\right)-\pi^{B N}}=\frac{(2-s)^{2}[s(1+s)-1]}{(2-s)^{2}[s(1+s)-1]+s^{4}}
$$

with $\delta_{B}^{*^{\prime}}=1 / 2$ if $s=1$.

\subsubsection{Partial collusion}

Here we deal with the performance of a cartel whose members' time preferences are below the thresholds identified above. The issue, in such a case, is to find the highest collusive price $p^{*} \in\left(p^{N}, p^{M}\right)$ sustainable over time, given $\delta$. If all firms set the collusive output $p^{*}$, the per-period profits of each cartel member are

$$
\pi^{C}=\frac{\left(a-p^{*}\right) p^{*}}{1+s}
$$

Again, the optimal deviation against the cartel price will take two different forms, depending on the degree of substitutability $s$. If the latter is sufficiently low (i.e., product differentiation between the two varieties is high enough), the deviator will adopt its best reply to cartel pricing solving (12) in which one has to plug $p_{j}=p^{*}$, to get the optimal deviation price

$$
p^{D}\left(p^{*}\right)=\frac{a(1-s)+s p^{*}}{2} .
$$

This generates the following one-off deviation profits

$$
\pi^{D}\left(p^{*}\right)=\frac{\left[a(1-s)+s p^{*}\right]^{2}}{4\left(1-s^{2}\right)},
$$

provided that the cheated firm is still active, i.e., it must be selling a positive quantity $q^{c h}$. This happens if

$$
q^{c h}=\frac{1}{2}\left[a-p^{*}-\frac{p^{*}}{2(1-s)}+\frac{2\left(a-p^{*}\right)+p^{*}}{2(1+s)}\right]>0
$$

which requires

$$
p^{*} \in\left[p^{N}, \frac{a(1-s)[2+s(6-s)]}{2-s^{2}}\right) \text {. }
$$


In this price range, condition (11) yields the following highest collusive price

$$
p^{*}=\frac{a(1-s)[4-s(1-\delta)(1-s)]}{(2-s)\left[4(1-s)+s^{2}(1-\delta)\right]}
$$

which is monotonically increasing in $a$ and lower than $p^{M}$ for all admissible values of $s$ and $\delta$.

Now we turn our attention to the collusive price range wherein any unilateral deviation makes the cheating firm a monopolist, driving all loyal cartel members out of business. This happens if expression (29) is non positive, i.e., for all

$$
p^{*} \in\left[\frac{a(1-s)[2+s(6-s)]}{2-s^{2}}, \frac{a+c}{2}\right]
$$

with

$$
\begin{gathered}
\frac{a+c}{2} \geq \frac{a(1-s)[2+s(6-s)]}{2-s^{2}} \\
\quad \text { for all } s \in[\sqrt{3}-1,1] .
\end{gathered}
$$

Imposing $q^{C h}=0$ yields the deviation price

$$
p^{D^{\prime}}\left(p^{*}\right)=\frac{p^{*}-a(1-s)}{s}
$$

which in turn delivers the deviation profits

$$
\pi^{D^{\prime}}\left(p^{M}\right)=\frac{\left(a-p^{*}\right)\left[p^{*}-a(1-s)\right]}{4 s^{2}} .
$$

It can be easily checked that $p^{D^{\prime}}\left(p^{*}\right)=p^{D}\left(p^{*}\right)$ in correspondence of

$$
p^{*}=\frac{a(1-s)[2+s(6-s)]}{2-s^{2}} \text {. }
$$

Plugging the above expression in the stability condition (11) and solving w.r.t. $p^{*}$, one obtains

$$
p_{ \pm}^{*^{\prime}}=\frac{a\left[4-(5-2 s) s^{2}-\delta(2-s)^{2}(1+s) \pm s \sqrt{\Phi}\right]}{2(2-s)\left[(1-\delta)(1+s)-s^{2}\right]}
$$


in which

$\Phi=\delta^{2}\left[(4+s) s-(2-s) s^{3}\right]+\delta\left[(2 s-1) s^{2}-4(1-s)-(4+s) s\right]+(2-s)^{2}$.

One can verify that $\Phi>0$, by solving $\Phi=0$ w.r.t. $\delta$ and checking that the resulting solutions $\delta_{ \pm} \neq \mathcal{R}$ for all $s \in[\sqrt{3}-1,1]$. Therefore, $\Phi$ has the same sign as the coefficient of $\delta^{2}$ in (38), which is positive, as can be easily ascertained. Moreover, the denominator of $p_{ \pm}^{*^{\prime}}$ is positive for all $s$ and $\delta$ in the unit interval.

The next step consists in observing that

$$
\frac{a(1-s)[2+s(6-s)]}{2-s^{2}}<p_{-}^{*^{\prime}}<\frac{a}{2}<p_{+}^{*^{\prime}}
$$

for all $\delta<\delta_{B}^{*^{\prime}}$. Accordingly, we select $p_{-}^{*^{\prime}}$ as the optimal collusive price in the admissible parameter range identified by

$$
\delta \in(\underline{\delta}, \bar{\delta}) \text { and } s \in[\sqrt{3}-1,1] .
$$

The partial derivative of $p_{+}^{*^{\prime}}$ w.r.t. $a$ is:

$$
\frac{\partial p_{-}^{*^{\prime}}}{\partial a}=\frac{(2-s)\left[(1-\delta)(2+s)-s^{2}(2-\delta)\right]-s \sqrt{\Phi}}{2(2-s)\left[(1-\delta)(1+s)-s^{2}\right]}
$$

Therefore, relying on the fact that $\Phi>0$, we may evaluate the sign of the numerator of $\partial p_{-}^{*^{\prime}} / \partial a$ by evaluating the sign of

$$
(2-s)^{2}\left[(1-\delta)(2+s)-s^{2}(2-\delta)\right]^{2}-s^{4} \Phi
$$

which turns out to be positive for all $\delta \in[0, \widetilde{\delta})$. The latter result, together with Lemma 3, implies that $\partial p_{-}^{*^{\prime}} / \partial a>0$ in the entire admissible range (40). Hence, the foregoing discussion allows us to formulate:

Lemma 2 In the Bertrand supergame under perfect certainty, any increase (resp., decreases) in consumers' reservation price increases (resp., decreases) the intensity of partial collusion, for any degree of product differentiation and irrespective of whether unilaterial deviation from the collusive path grants the cheating firm monopoly power or not. 


\section{Bridging two visions}

What we have reviewed so far boils down to the following two synthetic and seemingly antithetic messages:

i] if goods are undifferentiated and the market is subject to stochastic shoks affecting consumers' reservation price, then firms' pricing behaviour exhibits a definite countercyclical pattern;

ii] if goods are differentiated and the demand level is deterministic, then optimal cartel prices are always monotonically related to the reservation price, heedless of firms' time preferences.

Our aim in this section is to develop anew a model in which product differentiation and uncertainty operate together, so as to see whether the above conclusions may indeed be compatible with each other. As a first step, we will examine the case in which duopolistic competition survives unilateral deviations from cartel pricing. The second step will be to look at the opposite case where the defecting firm attains a monopolistic position.

On the supply side, the setup is the same as above. On the demand side, the demand function for firm $i$ will be:

$$
q_{i t}=\frac{\sigma_{t}}{1+s}-\frac{p_{i t}}{1-s^{2}}+\frac{s p_{j t}}{1-s^{2}},
$$

with $\sigma_{t} \in\{a, b\}, a>b>0$ and probabilities $\mathfrak{p}(a)=m$ and $\mathfrak{p}(b)=1-m$, respectively, with $m \in[0,1]$.

\subsection{Best reply deviation and the persistence of duopoly}

Here, the deviation price maximises $\pi^{D}$ and $q^{c h}>0$. We set out by taking a quick look at the stability condition for full collusion.

Monopoly price in state $\sigma_{t}$ is $p_{t}^{M}=\sigma_{t} / 2$, delivering expected per-firm cartel profits

$$
E \pi^{C}=\frac{m a^{2}+(1-m) b^{2}}{4(1+s)} .
$$

The deviation price and profits in correspondence of the best demand state correspond to (17) and (19), respectively, and apply for all $s \in[0, \sqrt{3}-1)$. 
The individual expected Bertrand-Nash profits in each period of the punishment phase are given by

$$
E \pi^{N}=\frac{\left[m a^{2}+(1-m) b^{2}\right](1-s)}{(1+s)(2-s)^{2}}
$$

As a result, collusive stability now requires

$$
\delta \geq \frac{a^{2}(2-s)^{2}}{a^{2}\left[4 m(1-s)-(2-s)^{2}\right]+b^{2}(1-m)^{2}(1-s)^{2}} \equiv \delta^{*},
$$

with

$$
\frac{\partial \delta^{*}}{\partial a} \propto(1-m)(1-s)>0 \forall m \in[0,1) ; s \in[0, \sqrt{3}-1)
$$

and

$$
\frac{\partial \delta^{*}}{\partial m} \propto-(1-s)<0 \forall s \in[0, \sqrt{3}-1) .
$$

As for partial collusion, define

$$
E \pi^{C}=\frac{m\left(a-p^{*}(a)\right) p^{*}(a)+(1-m)\left(b-p^{*}(b)\right) p^{*}(b)}{1+s}
$$

with $p^{*}(b)=b / 2$, in such a way that the only unknown is the partially collusive price in the best state, $p^{*}(a)$. That is, we assume firms will charge the best collusive price in the worst state, and appropriately tune $p^{*}(a)$ so as to satisfy the stability condition (11), which we are about to construct step by step.

Accordingly, the best deviation against $p^{*}(a)$ along the reaction function is

$$
p^{D}\left(p^{*}(a)\right)=\frac{a(1-s)+s p^{*}(a)}{2} .
$$

Then the expected payoff in each period of the punishment phase is (45). From the usual stability condition, we get the pair of solutions:

$p(a)_{ \pm}^{*}=\frac{a(2-s)(1-s) \Theta \pm 2 \delta(1-s) s \sqrt{\Psi}}{(2-s)\left[s^{2}(1-\delta)+4(1-s)\right]\left[(2-s)^{2}-\delta\left(4 m(1-s)-(2-s)^{2}\right)\right]}$

where

$$
\Theta=[2 \delta m+(2-s)(1-\delta)]\left[s^{2}(1-\delta)+4(1-s)\right]>0
$$


and

$$
\begin{gathered}
\Psi=a^{2} m^{2}\left[s^{2}(1-\delta)+4(1-s)\right]^{2}+ \\
4 b^{2}(2-s)^{2}(1-\delta)(1-m)\left[(2-s)^{2}-\delta\left(4 m(1-s)-(2-s)^{2}\right)\right]>0 .
\end{gathered}
$$

It is then easily checked that

$$
\lim _{m \rightarrow 1} p(a)_{-}^{*}=\frac{a(1-s)[4-s(1-\delta)(1-s)]}{(2-s)\left[4(1-s)+s^{2}(1-\delta)\right]}=p^{*}
$$

i.e., the same price as in (31). Finally, taking the partial derivative of $p(a)_{-}^{*}$ w.r.t. $a$, one can verify that

$$
\begin{gathered}
\frac{\partial p_{-}^{*}}{\partial a} \propto a^{2} m^{2}\left[s^{2}(1-\delta)+4(1-s)\right]\left[(2-s)^{2}(1-\delta)+4 m\right]+ \\
4 b^{2}(2-s)^{4}(1-\delta)(1-m)[2 \delta m+(2-s)(1-\delta)]^{2}>0
\end{gathered}
$$

everywhere.

Therefore, we can state

Proposition 3 If deviation from the collusive path does not grant monopoly power, then the maximum collusive price sustainable under stochastic demand conditions is monotonically increasing in the level of the best demand state.

\subsection{Defecting to monopoly}

The last step consists in investigating the case in which a unilateral deviation from the cartel price turns the deviator into a monopolist. Under full collusion, the only detail that has to be modified is the deviation price in correspondence of the best state, which causes the cheated firm's output to drop to zero. This is (21), ensuring the deviation profits (22) for all $s \in[\sqrt{3}-1,1]$. The resulting stability condition is

$$
\delta \geq \frac{a^{2}(2-s)^{2}[(1+s) s-1]}{a^{2}\left[s^{4}(m+1)+4(4 s-1)-s^{2}(1+3 s)\right]+b^{2}(1-m) s^{4}} \equiv \delta^{*^{\prime}},
$$

with $\partial \delta^{*^{\prime}} / \partial a>0$ and $\partial \delta^{*^{\prime}} / \partial m<0$ for all $s \in[\sqrt{3}-1,1]$, so that the picture remains much the same as we already know it, along the frontier of industry profits. 
Now suppose firms' time preferences fall short of (56). If so, they may activate the highest sustainable degree of partial collusion. In such a case, they set $p^{*}(b)=b / 2$ whenever demand is low, and solve the stability condition w.r.t. $p^{*}(a)$, obtaining:

$$
p_{ \pm}^{*^{\prime}}(a)=\frac{a(2-s)\left[(1-\delta)(2-s(2 s-1))-\delta m s^{2}\right] \pm s \sqrt{\Gamma}}{2(2-s)\left[(1-\delta)(1+s(1-s))-\delta m s^{2}\right]}
$$

in which

$$
\begin{gathered}
\Gamma=a^{2}\left[s^{2}(1-\delta(1-m s))^{2}+\right. \\
4(1-\delta)((1-\delta)(1-s)-\delta m(2 s-1))] \\
-b^{2} \delta s^{2}(1-m)\left[(1-\delta)(1+s(1-s))-\delta m s^{2}\right]
\end{gathered}
$$

with

$$
\begin{gathered}
(1-\delta)(2-s(2 s-1))-\delta m s^{2}>0 \\
s^{2}(1-\delta(1-m s))^{2}+4(1-\delta)((1-\delta)(1-s)-\delta m(2 s-1))>0
\end{gathered}
$$

and

$$
-\delta s^{2}(1-m)\left[(1-\delta)(1+s(1-s))-\delta m s^{2}\right]<0
$$

for all $\delta$ and $m$ in the unit interval and all $s \in[\sqrt{3}-1,1]$. In the same parameter region, one also has that (i) $\Gamma>$ for all

$$
\frac{a^{2}}{b^{2}}>\frac{\delta s^{2}(1-m)\left[(1-\delta)(1+s(1-s))-\delta m s^{2}\right]}{s^{2}(1-\delta(1-m s))^{2}+4(1-\delta)((1-\delta)(1-s)-\delta m(2 s-1))}
$$

with the threshold on the r.h.s. of (62) being always lower than one (hence, both $p_{-}^{*^{\prime}}(a)$ and $p_{+}^{*^{\prime}}(a)$ are real), and (ii) $p_{-}^{*^{\prime}}(a)$.

To identify the correct solution, it suffices to verify that

$$
\lim _{m \rightarrow 1} p_{-}^{*^{\prime}}(a)=\frac{a\left[4-(5-2 s) s^{2}-\delta(2-s)^{2}(1+s)-s \sqrt{\Phi}\right]}{2(2-s)\left[(1-\delta)(1+s)-s^{2}\right]}=p_{-}^{*^{\prime}} .
$$

The last step consist in differentiating $p_{-}^{*^{\prime}}(a)$ w.r.t. $a$, defining $a=r b$ with $r>1$ and then solving $\partial p_{-}^{*^{\prime}}(a) / \partial a=0$ w.r.t. $r$, getting ${ }^{6}$

$r=\frac{s(2-s)\left[(1-\delta)(2-s(2 s-1))-\delta m s^{2}\right] \sqrt{\delta(1-m)\left[(1-\delta)(1+s(1-s))-\delta m s^{2}\right]}}{2 \sqrt{(1-s) \Omega}}=\bar{r}$

\footnotetext{
${ }^{6}$ The second solution can be disregarded as it is always negative.
} 
with

$$
\begin{gathered}
\Omega=\left[(1-\delta)(1+s(1-s))-\delta m s^{2}\right]\left[\delta m s^{2}-(1-\delta)(2-s)^{2}(1+s)\right] \times \\
{\left[s^{2}(1-\delta(1-m s))^{2}+4(1-\delta)((1-\delta)(1-s)+\delta m(2 s-1))\right] .}
\end{gathered}
$$

Now, it can be shown analytically that $r \in \mathcal{R}^{+}$; moreover,

$$
\begin{gathered}
\lim _{m \rightarrow 1} r=0 \text { and } \\
\lim _{m \rightarrow 0} r=\frac{s\left[2\left(1-s^{2}\right)+s\right] \sqrt{\delta}}{(2-s) \sqrt{(1-\delta)\left(1-s^{2}\right)}}>1
\end{gathered}
$$

for all

$$
\delta>\frac{(2-s)^{2}\left(1-s^{2}\right)}{s^{2}+4\left[1-s(1+s(1-s))(1-s)\left(1-s^{2}\right)\right]}=\underline{\delta}
$$

which is decreasing and concave in $s$, with $\underline{\delta}=3(39+38 \sqrt{3}) / 937 \simeq 0.336$ in $s=\sqrt{3}-1$ and $\underline{\delta}=0$ in $s=1$. Consequently, we have that

$$
\frac{\partial p_{-}^{*^{\prime}}(a)}{\partial a}>0 \text { for all } r>\max \{1, \bar{r}\}
$$

and conversely between one and $\bar{r}$, if indeed $\bar{r}>1$. In general, $\bar{r}$ is decreasing and concave in $m$ (this can ve ascertained numerically), and will give rise to a picture like the one reported in Figure 2, in which "+" and "-" signs indicate the sign of $\partial p_{-}^{*^{\prime}}(a) / \partial a$. 
Figure 2: Collusive pricing in the space $(m, r)$.

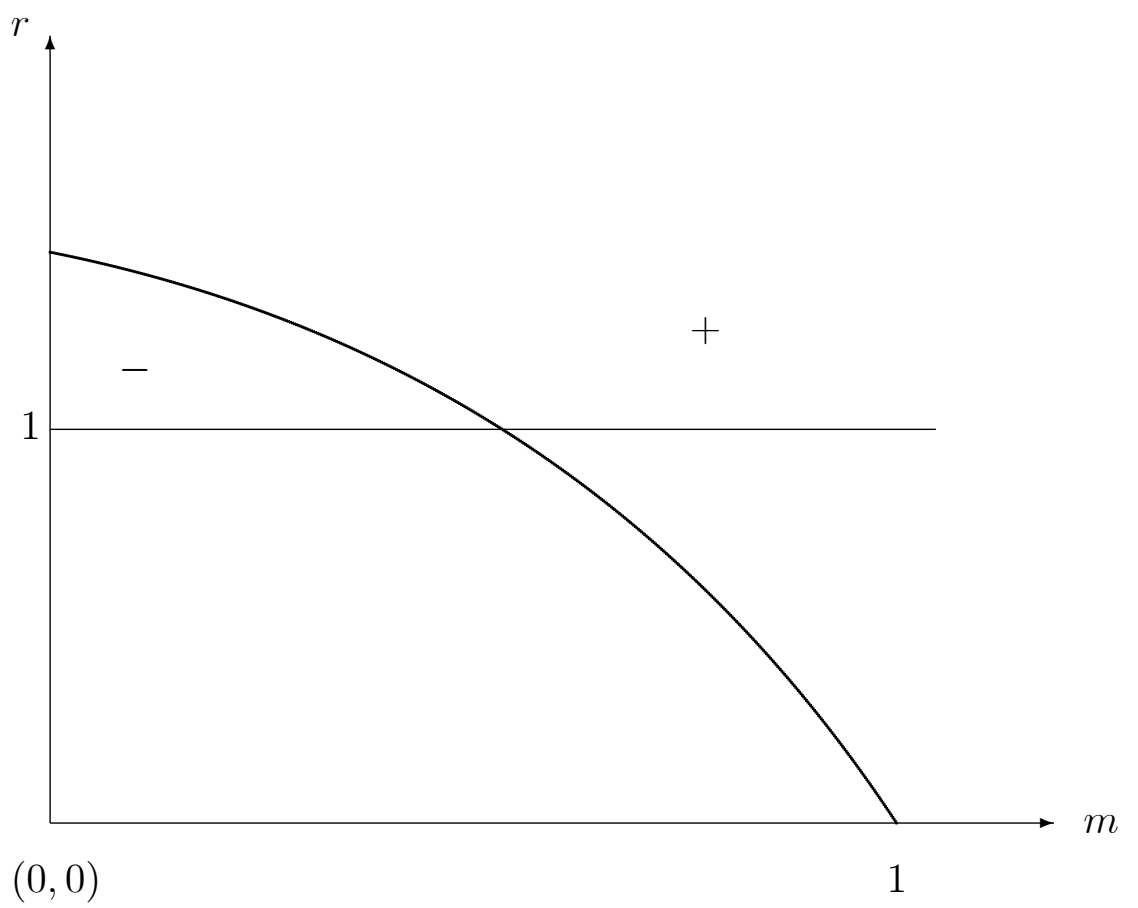

To sum up, above the upper envelope $\partial p_{-}^{*^{\prime}}(a) / \partial a>0$; if $\bar{r}>1$ for at least some acceptable parameter values, then in such a region $\partial p_{-}^{*^{\prime}}(a) / \partial a<0 .^{7}$

An analogous exercise can be carried out in the space $(s, a)$ as well as in $(\delta, a)$. This is done in Figures 3 and 4, respectively. In particular, Figure 3 shows that countercyclical pricing emerges in the region in which $r \in(1, \bar{r})$ and the two product varieties are sufficiently close substitutes. It is also worth observing that $\bar{r}$ asymptotically increases to infinity as $s$ approaches 1 in the limit, in which case pricing is countercyclical irrespective of $r$, as in Rotemberg and Saloner's (1986) original formulation.

\footnotetext{
${ }^{7}$ Recall that in state $b$, by assumption, firms collude on the monopoly frontier.
} 
Figure 3: Collusive pricing in the space $(s, r)$.

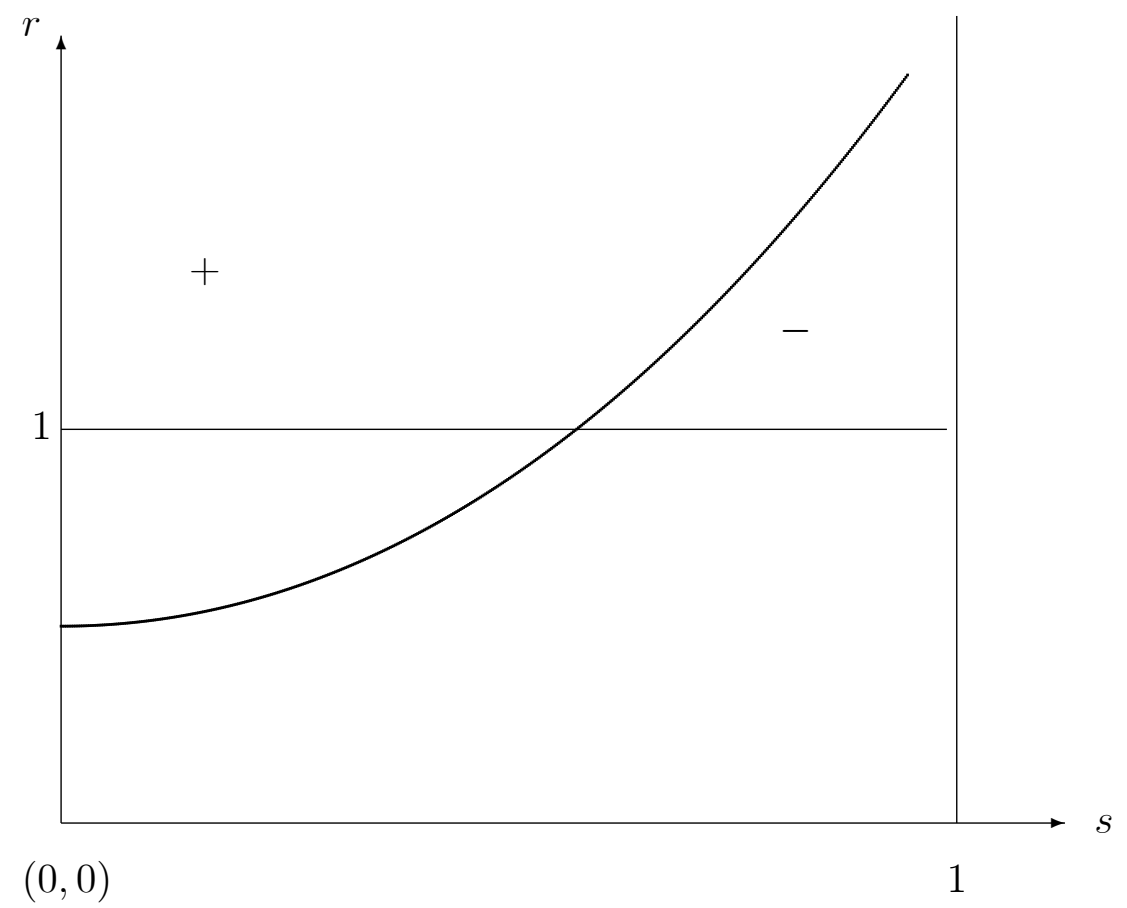


Figure 4: Collusive pricing in the space $(\delta, r)$.

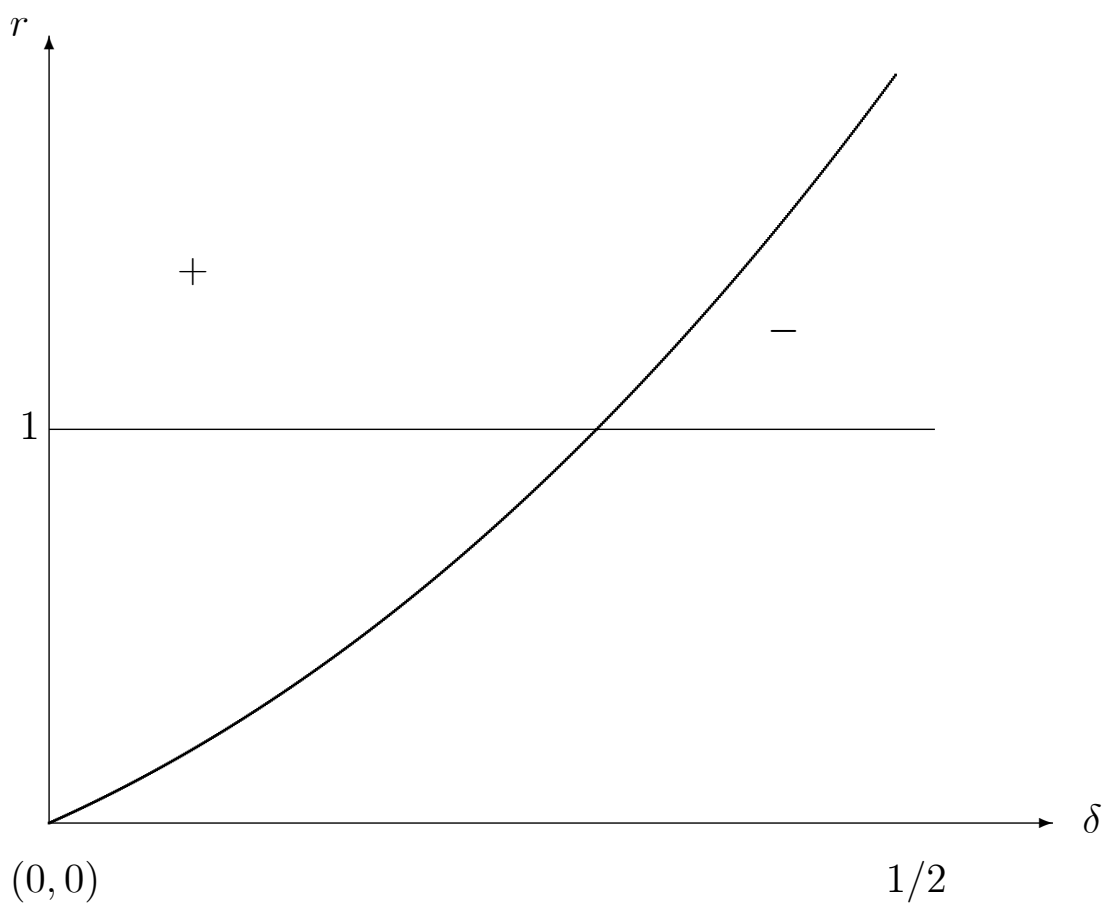

Our final result can be therefore stated as follows:

Proposition 4 If deviation from the collusive path grants monopoly power, then the maximum collusive price sustainable under stochastic demand conditions is monotonically decreasing (increasing) in the level of the best demand state if product differentiation is low (high) enough.

\section{Concluding remarks}

The effective size of government spending multipliers is a crucial macroeconomic issue, especially after the massive fiscal stimuli of 2009-2010 and the need for spending cuts which is becoming more and more pressing. In imperfectly competitive frameworks, multipliers'size is increasing function of mark-up countercyclicality but decreasing function of its procyclicality. As a 
consequence, determining the effective direction of pricing cyclicality becomes crucial for the analysis of a government spending stimulus on agggregate activity.

We have used a repeated duopoly game to revisit the issue of cyclical pricing so as to reconcile Rotemberg and Saloner's (1986) results about the emergence of countercyclical pricing under uncertainty with the procyclical flavour traditionally associated with implicit collusion in the perfect certainty approach typical of the large debate on this topic in the theory of industrial organization.

The bottom line of our analysis is that the cyclical properties of firms' pricing behaviour are sensitive to the degree of product differentiation across product varieties, in such a way that pricing is procyclical whenever the cheated firm retains a positive market share during deviations (because products are weak substitutes), while instead counterciclicity indeed obtains provided that (i) the deviator becomes a monopolist and (ii) product differentiation is sufficiently low.

Mark-up cyclical behaviour might therefore be a far more complicated issue than previously thought, with relevent consequences on the actual effects of expansionary expenditure-based fiscal policies. Future research will be concerned with an empirical analysis attempting to link different sectors (featured by different degrees of product differentiation) with different cyclical properties of their average mark-ups. 


\section{References}

[1] Albæk, S. and L. Lambertini (1998), "Collusion in Differentiated Duopolies Revisited", Economics Letters, 59, 305-8.

[2] Bagwell, K. and R. Staiger (1997), "Collusion Over the Business Cycle", RAND Journal of Economics, 28, 82-106.

[3] Bils, M., (1987), "The Cyclical Behavior of Marginal Costs and Price", American Economic Review, 77, 838-55.

[4] Canzoneri, M., F. Collard, H. Dellas and B. Diba (2011), "Fiscal Multipliers in Recessions", mimeo.

[5] Chang, M.H. (1991), "The Effects of Product Differentiation on Collusive Pricing", International Journal of Industrial Organization, 9, 45369 .

[6] Chang, M.H. (1992), "Intertemporal Product Choice and Its Effects on Collusive Firm Behavior", International Economic Review, 33, 773-93.

[7] Chevalier, J.A., A.K. Kashyap and P.E. Rossi (2003), "Why Don't Prices Rise During Periods of Peak Demand? Evidence from Scanner Data", American Economic Review, 93, 15-37.

[8] Chirinko, R.S. and M. Fazzari (1994), "Economic Fluctuations,Market Power and Returns to Scale: Evidence from Firm-Level Data", Journal of Applied Econometrics, 9, 509-13.

[9] Donowitz, I.R., G. Hubbard and B.C. Petersen (1986), "Business Cycles and the Relationship Between Concentration and Price-Cost Margins", Rand Journal of Economics, 17, 1-17.

[10] Donowitz, I.R., G. Hubbard and B.C. Petersen (1988), "Market Structure and Cyclical Fluctuations in US Manufacturing", The Review of Economics and Statistics, 70, 55-66.

[11] Deneckere, R. (1983), "Duopoly Supergames with Product Differentiation", Economics Letters, 11, 37-42.

[12] Etro, F. and A. Colciago (2010), "Endogenous Market Structure and the Business Cycle", Economic Journal, 120, 1201-33. 
[13] Friedman, J.W. (1971), "A Non-Cooperative Equilibrium for Supergames", Review of Economic Studies, 28, 1-12.

[14] Galì, J., (2005), "Modern Perspective on Fiscal Stabilization Policies", CESifo Economic Studies, 51, 587-99.

[15] Galì, J., M. Gertler and J.D. Lopez-Salido (2005), "Mark-ups, Gaps and the Welfare Costs of Business Cycle Fluctuations", mimeo, CREI.

[16] Ghironi, F. and M. Melitz (2005), "International Trade and Macroeconomic Dynamics with Heterogenous Firms", Quarterly Journal of Economics, 120, 865-915.

[17] Hall, R. (2009), "By How Much does GDP Rises if the Government Buys More Output?", NBER Working paper 15496.

[18] Haltiwanger, J. and J. Harrington (1991), "The Impact of Cyclical Demand Movements on Collusive Behaviour", RAND Journal of Economics, 22, 89-106.

[19] Jaimovich, N. and M. Floetotto (2008), "Firm Dynamics, Mark-Up Variations and the Business Cycle", Journal of Monetary Economics, 55, 1238-52.

[20] Lambertini, L. (1997), "Prisoners' Dilemma in Duopoly (Super)Games", Journal of Economic Theory, 77, 181-91.

[21] Majerus, D. (1988), "Price vs Quantity Competition in Oligopoly Supergames", Economics Letters, 27, 293-7.

[22] Martins, J., S. Scapetta and D. Pilat (1996), "Markup Pricing, Market Structure and the Business Cycle", OECD Economic Studies, 27, 71105.

[23] Nekarda, C. and V. Ramey (2010), "The Cyclical Behavior of the PriceCost Markup", mimeo, University of California, San Diego.

[24] Portier, F. (1995), "Business Formation and Cyclical Markups in the French Business Cycle", Annales d'Economie et de Statistique, 37, 41140. 
[25] Ross, T.W. (1992), "Cartel Stability and Product Differentiation", International Journal of Industrial Organization, 10, 1-13.

[26] Rotemberg, J. and G. Saloner (1986), "A Supergame-Theoretic Model of Price Wars during Booms", American Economic Review, 76, 390-407.

[27] Rotemberg, J. and M. Woodford (1999), "The Cyclical Behaviour of Prices and Costs", in J.B. Taylor and M. Woodford (eds), Handbook of Macroeconomics, 1 (B), 1051-1135.

[28] Rotemberg, J. and M.Woodford (1992), "Oligopolistic Pricing and the Effects of Aggregate Demand on Economic Activity", Journal of Political Economy, 100, 1153-1207.

[29] Rothschild, R. (1992), "On the Sustainability of Collusion in Differentiated Duopolies", Economics Letters, 40, 33-7.

[30] Singh, N. and X.Vives (1984), "Price and Quantity Competition in a Differentiated Duopoly", RAND Journal of Economics, 15, 546-54.

[31] Spence, M. (1976), "Product Differentiation and Welfare", American Economic Review, 66, 407-14.

[32] Tirole, J. (1988), The Theory of Industrial Organization, Cambridge, MA, MIT Press.

[33] Woodford, M., (2003), Interest and Prices. Foundations of a Theory of Monetary Policy, Princeton, NJ, Princeton University Press.

[34] Woodford, M., (2011), "Simple Analytics of the Government Expenditure Multiplier", American Economic Journal: Macroeconomics, 3, $1-35$. 


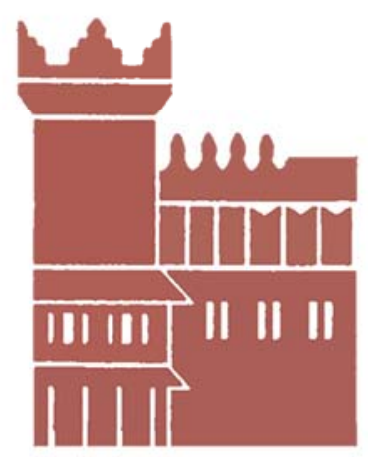

Alma Mater Studiorum - Università di Bologna DEPARTMENT OF ECONOMICS

Strada Maggiore 45

40125 Bologna - Italy

Tel. +39051 2092604

Fax +390512092664

http://www.dse.unibo.it 